\title{
La difícil colonización del Oriente Venezolano. Francisco de Vides y la expedición pobladora de 1592
}

\author{
M. ${ }^{a}$ José Nestares Pleguezuelo \\ Universidad de Almería
}

\begin{abstract}
El presente trabajo analiza la labor pobladora que ejerció el gobernador de Nueva Andalucía, Francisco de Vides, durante los años 1592 a 1597, merced al contingente colonizador que trajo consigo desde la Península Ibérica. Se cuestionan las causas que motivaron a la Corona para nombrar a su gobernador mediante una capitulación. Se estudia el origen y la composición de la expedición pobladora, la figura de Vides al frente de la gobernación, los conflictos que originó, las causas de la despoblación y el proceso judicial que se levantó contra él.
\end{abstract}

\section{El Oriente venezolano a finales del siglo XVI}

El extremo oriental de la Tierra Firme, que comprendía el arco costero entre el Morro de Unare y la entrada al Amazonas, así como las islas que se encontraban frente al litoral, se articulaba a finales del siglo XVI en tres gobernaciones: Nueva Andalucía, Margarita y Trinidad-Guayana.

El proceso de colonización, teniendo en cuenta las fechas en que éste había comenzado en las principales áreas del territorio americano, se hallaba algo desfasado. Además, las tres demarcaciones señaladas presentaban un grado de incorporación a la Corona española muy diferente.

La de Margarita mostraba un nivel más elevado de transición de la conquista a la colonización. En 1525, en que fue firmada la capitulación con Marcelo de Villalobos, ${ }^{1}$ se inició un proceso de asentamiento que estaba claramente concluido al finalizar la centuria.

El área de Trinidad-Guayana se encontraba, por el contrario, en los primeros estadios de la colonización. En la gobernación de Trinidad, concedida para su pacificación en diferentes ocasiones desde 1530, no se había conseguido levantar ningún centro estable. Entre 1588 y 1591, en que se incorporó a la Nueva Andalucía, tampoco se logró concluir la etapa pobladora. Será a partir de 1592, a raíz de su unión al área guayanesa, cuando se funden las dos primeras ciudades: San José de Oruña, en Trinidad, y Santo

1 Morón Montero, Guillermo: Breve Historia de Venezuela. Madrid, 1979, pág. 59. 
Tomé, en la Guayana, aunque no se adelante mucho más en la política de poblamiento debido a los enfrentamientos que mantuvo su gobernador, Antonio de Berrío, ${ }^{2}$ contra las pretensiones territoriales de la gobernación cumanesa y los ataques piráticos de Sir Walter Raleigh.

La tercera de estas gobernaciones orientales, la de Nueva Andalucía, atravesaba una etapa intermedia entre las dos anteriores, con notables contrastes en su extenso territorio, pues mientras en la franja costera se estaba perfeccionando el proceso de colonización, la vasta zona del interior estaba aún pendiente de conquista y pacificación.

\section{Los intentos pacificadores en la costa de Tierra Firme}

En el extremo oriental de la Tierra Firme los españoles encontraron una zona habitada por unas pocas tribus de indios belicosos que ofrecieron una gran resistencia al proceso de poblamiento. A esta inicial dificultad se unía una peculiaridad geográfica. Su localización, a medio camino entre el Atlántico y el Caribe, la cercanía de las incipientes posesiones extranjeras, la gran profusión de islas, y el aspecto recortado de sus costas, convirtieron a la zona, desde un primer momento, en un lugar de gran importancia estratégica.

El conocimiento español de la zona data de los años 1499-1500, cuando se produjeron los primeros reconocimientos de la costa. ${ }^{3}$ Durante la primera mitad del siglo XVI se sucedieron diferentes ensayos evangelizadores por parte de misioneros franciscanos y dominicos, pero todos terminarían violentamente a causa de la oposición indígena.

La historia de la gobernación de Nueva Andalucía comienza con la capitulación firmada en 1568 entre Diego Fernández de Serpa y la Corona, ${ }^{4}$ por la que se le otorgaba al primero el título de gobernador y capitán general, a cambio de dar comienzo a esta pacificación. ${ }^{5}$ La ciudad de Cumaná fue fundada en 1569 , convirtiéndose en el primer centro urbano del territorio sin solución de continuidad. ${ }^{6}$

\footnotetext{
2 Ojer, Pablo: Don Antonio de Berrío, gobernador del Dorado. Caracas, 1960, y Morón Montero, Guillermo: Breve Historia ..., pág. 68.

3 Gómez, José Mercedes: Orígenes históricos de la ciudad de Cumaná. Cumaná, 1973.

4 Marcano, Pedro Elías: Consectario de la ciudad de Cumaná. Caracas, 1956 (2. a ed.).

5 Sucre, Luis Alberto: Cumaná. Su fundador el capitán Diego Fernández de Serpa. Caracas, 1929 , pág. 10 y ss.

6 Sobre la fundación de Cumaná ver Martínez-Mendoza, Jerónimo: "La fecha de la fundación de Cumaná”, y Ojer, Pablo: “Cuando se fundó la ciudad de Cumaná?”, ambos en el Boletín de la Academia Nacional de la Historia, n. ${ }^{\circ}$ 191, Caracas, 1965.
} 
A Serpa se le concedía un territorio que comprendía "el girón de tierra" hasta el Morro de Unare, lo que implicaba la inclusión en la joven gobernación de la región de los Cumanagotos, zona que pertenecía a la de Venezuela desde 1528. Esta franja de tierra, entre los ríos Unare y Neverí, habitada por los indios cumanagotos y chacopatas, había despertado el interés de los españoles en diferentes ocasiones, pero su pacificación se había mostrado casi imposible. De las numerosas expediciones organizadas para ese fin, y los intentos por establecer en ella una fundación estable, sólo pervivió la que en 1585 erigieron los caraqueños con el nombre de San Cristóbal de la Nueva Écija de Cumanagotos. Por motivos que exceden al propósito de nuestro estudio, Caracas acabó por ceder el poblado y toda la región a Cumaná, y desde entonces la consolidación del área se convirtió en objetivo preferente de los gobernadores neoandaluces. ${ }^{7}$

La labor del portugués Manuel Núñez Lobo, gobernador entre 1587 y 1589 , se centró en el reforzamiento de aquella ciudad y para ello incorporó un mayor número de pobladores y la rebautizó con el nombre de San Felipe de Cumanagotos. Su misión en las tierras occidentales se completó a mediados de 1588 con la fundación de un nuevo centro: Nuestra Señora de la Victoria, a cuatro leguas del ya existente, aunque éste último no logró consolidarse.

Contra la labor de Núñez Lobo se formó una vasta oposición, especialmente por parte de la Audiencia de Santo Domingo y del Cabildo cumanés. Fue acusado de no haber cumplido con lo pactado en su capitulación y, a pesar del apoyo que le dispensaron los propios pobladores, no pudo evitar ser separado de su gobernación. Los defensores de Núñez Lobo se convirtieron en fuertes opositores del recién llegado Vides, hasta el punto que serían los principales causantes de su caída en desgracia.

\section{La actividad pobladora del gobernador Francisco de Vides}

La llegada en 1592 del nuevo gobernador, Francisco de Vides, con un fuerte efectivo poblacional procedente de la metrópoli, iba a dar un importante impulso a la colonización del territorio, a pesar de que su gobierno está considerado como uno de los más conflictivos del Oriente Venezolano. La oposición que encontró a su llegada, más la que se ganó con su despó-

7 Ojer, Pablo: La formación del Oriente Venezolano. Tomo 1. Creación de las gobernaciones. Caracas, 1966, pág. 420 y ss. 
tico ejercicio del poder, lo implicaron en numerosas causas judiciales. Sin embargo, las acusaciones vertidas contra su persona no son suficientes para explicar los numerosos pleitos ni el duro castigo que sufrió por ellos. Es necesario analizar su actividad al frente de la gobernación para conocer las razones que le llevaron en tan numerosas ocasiones ante los tribunales y a terminar sus días entre rejas.

La tarea no es sencilla. Ojer, que ha analizado gran parte de estos pleitos, afirma que es difícil valorar su gobierno pues, aunque los documentos son copiosos, también son contradictorios y contienen serios errores. ${ }^{8}$ Nosotros vamos a intentar, a lo largo de estas líneas, analizar su política pobladora, el origen de las acusaciones vertidas contra su persona y, en último término, su aportación a la consolidación del oriente venezolano.

\section{Los primeros contactos de Vides con la Nueva Andalucía}

Francisco de Vides, nacido en torno al año 1539, en Trigueros, provincia de Huelva, debió embarcarse en edad relativamente temprana hacia América, y antes de la obtención del gobierno de Cumaná era ya un hombre con un prestigioso currículum. Había participado en la conquista de los caracas y en la fundación de la capital, donde ejerció el cargo de alcalde y contador, poseía encomiendas, tierras, hatos y casas en aquella provincia y había dirigido personalmente algunas expediciones contra los indígenas.

Su relación con el oriente venezolano comienza a finales de 1589 , fecha en la que la Real Audiencia de Santo Domingo lo nombra gobernador interino para suceder a Rodrigo Núñez Lobo. En febrero del año siguiente toma posesión del cargo, pero apenas unos meses después el organismo dominicano dicta la privación de empleo a causa de una querella que el gobernador de Cuba había interpuesto contra él, ${ }^{9}$ por lo que tras la información de varios testigos, fue encarcelado.

Los verdaderos autores de la acusación habían sido los partidarios de Núñez Lobo, enemistados con Vides por la dureza con la que éste había pro-

8 Ojer (La formación..., pág. 436), al mencionar las inexactitudes vertidas sobre la actuación de Vides se refiere, en concreto, al padre Caulín. Este debía su error a haberse basado para el retrato del gobernador en un informe que Francisco Rodríguez Leyte dirigió a los padres franciscanos de la Provincia de Santa Cruz, fechado en Barcelona, 17 de abril de 1647, conservado en el Archivo General de Indias (en adelante AGI), Santo Domingo, 641.

9 AGI, Escribanía de Cámara, 1011A. Provisión de la Audiencia al gobernador de La Habana, Juan de Tejada. Santo Domingo, 14 de julio de 1590. 
cedido en el juicio de residencia de su antecesor. Se basaban aquellos en la complicidad que el triguereño había tenido en el juicio que el juez Agüero había seguido contra el hijo del gobernador de Venezuela, Juan de Rojas.

La excelente defensa que ejerce su procurador, Miguel Azparren, ante la Corte, probando la ausencia de delito alguno con Agüero, el grado excesivo de la multa impuesta y la consideración acerca de que en el origen de este caso se encontraba el temor de los partidarios del ex-gobernador de Cumaná por el castigo que se les iba a imponer por su mala conducta, fue causa suficiente para que el Consejo de Indias declarara libre al inculpado, previa fianza y con obligación de presentarse ante la Corte para dar razón de sus actos. ${ }^{10}$

Vides aprovecha su declaración ante el Consejo de Indias para pedir, de forma vitalicia y por capitulación, la gobernación de Cumaná. ${ }^{11}$ Su justificación fue tan eficaz que no sólo se le restituye el gobierno de forma interina sino que lo obtiene en propiedad.

\section{Una capitulación a finales del siglo XVI}

Ricardo Zorraquín Becú señala que el sistema de nombrar gobernador por capitulación había concluído ya en 1574, siendo de 1565 el último pacto del que él tiene constancia. ${ }^{12}$ Resulta interesante analizar por ello por qué la Corona seguía manteniendo, nada menos que en 1592, la vieja fórmula de capitulación y, además, en un territorio que ya le pertenecía, no dejando que la designación siguiese el curso administrativo habitual, es decir, el nombramiento por parte de la Audiencia de Santo Domingo, como, por otro lado, ya se hacía en las demarcaciones vecinas.

La principal razón estriba en que para la Corona este territorio todavía no estaba descubierto, ni menos aún conquistado o pacificado. Lo estaba únicamente en la estrecha franja de tierra que formaba la costa, e incluso la totalidad de ésta hacía poco tiempo que podía ser considerada como plenamente incorporada. El interior de la gobernación y la totalidad de las islas de Trinidad, Granada y Tobago, estaban plenamente en manos indígenas.

10 Ibídem. Madrid, 13 de febrero de 1591.

11 AGI, Indiferente, 741, N. ${ }^{\circ} 276$. Informe del Consejo de Indias, Madrid, 31 de diciembre de 1591, favorable a la pretensión de Vides.

12 Zorraquín Becú, Ricardo: "Los distintos tipos de gobernador en el Derecho indiano", III Congreso del Instituto Internacional de Historia del Derecho Indiano. Madrid, 17-23 de enero de 1972. Actas y estudios. Madrid, 1973, pág. 543. 
La Corona era consciente de su incapacidad para acometer la colonización del territorio sin la ayuda de los particulares, tal y como expresaba el Consejo de Indias: "sin que sea posible que estas cosas se hagan por mano ni cuenta de Vuestra Majestad". ${ }^{13}$ Pero una capitulación exigía de la Corona la cesión de una serie de privilegios a manos de la otra parte contratante, y estas concesiones habían acarreado numerosos problemas a la administración en Indias a lo largo del siglo en curso. ${ }^{14}$ Podríamos pensar que en las postrimerías de la centuria estas prerrogativas se habrían limitado, pero no fue así. Como veremos unas líneas más abajo, Vides no sólo quedaba investido con la autoridad civil, militar y judicial, y por dos vidas, sino que recibía la posibilidad de encomendarse indios en esta gobernación.

Esto puede parecer contradictorio si tenemos en cuenta que desde algunas décadas atrás la legislación abogaba por la extinción de las encomiendas. Nosotros nos atrevemos a pensar que si la Corona se había mostrado tan espléndida en sus concesiones era porque no tenía intención de cumplirlas. Las obligaciones del gobernador eran excesivas y difícilmente podría llevarlas a cabo. La destitución del mandatario en caso de extralimitación en sus funciones, o de incumplimiento del pacto se abrían como magníficas oportunidades para la rescisión del contrato, como de hecho ocurrió con él y sus antecesores.

\section{La capitulación para descubrir, pacificar y poblar la gobernación de Nueva Andalucía}

El Consejo de Indias, que debía decidir acerca del mandatario que seguiría al frente de la gobernación neoandaluza, consideró a Francisco de Vides como el más capacitado por su edad, su experiencia y por las propiedades que había logrado reunir, ya que le serían "de gran socorro y ayuda

13 AGI, Indiferente, 741 N $^{\circ}{ }^{2} 276$ Informe... $^{2}$

14 La bibliografía hace referencia en numerosas ocasiones a los conflictos que se originaron entre la Corona y los conquistadores a raíz del vínculo de las capitulaciones. Se pueden ver los siguientes trabajos: Gómez Pérez, Carmen, y Marchena Fernández, Juan: "Los señores de la guerra en la conquista de América”, Anuario de Estudios Americanos, XLII, Sevilla, 1985, págs. 127-215; Marchena Fernández, Juan: "Los hijos de la guerra: modelo para armar", Congreso de Historia del Descubrimiento, T. III, Madrid, 1992, págs. 311-410; Serrera Contreras, Ramón María: "Derecho Premial y aspiraciones señoriales en la primera generación de la conquista”, Congreso... citado, T. III, págs. 481-502; y Pietschmann, Horst: El Estado y su evolución al principio de la colonización española de América. México, 1989, pág. 112. 
para poder mejor cumplir y meter allí los ganados y irse socorriendo con los mantenimientos y cosas necesarias en que cualquiera otro sentiría gran descomodidad". ${ }^{15}$

Pensando, además, que el documento debía firmarse con la mayor brevedad, para que el interesado y los pobladores partiesen junto a la primera flota hacia Indias, el Consejo comisionó al doctor Pedro Gutiérrez Florez y este preparó con el triguereño la capitulación aunque, antes, tuvieron que defenderse de una acusación dirigida contra el candidato a gobernador.

Al organismo había llegado un memorial, firmado por el lusitano Juan López, que decía ser el procurador de la provincia cumanesa, en el que se atribuían a Vides ciertos "crímenes y defectos" y, aunque el acusador no disponía de credenciales que dieran autenticidad a sus graves acusaciones, pareciendo más bien que era uno de los partidarios del ex-gobernador Núñez Lobo, se decidió dar curso a una averiguación, encomendándosela al mismo doctor Gutiérrez.

En el transcurso de la investigación llegaron al Consejo dos nuevos ofrecimientos para hacerse cargo de la gobernación neoandaluza, que serían rechazados. El de Juan Ponce de León, hijo de García Trobe, consistía, básicamente, en llevar 200 hombres desde la metrópoli y levantar otros 200 en el Nuevo Reino de Granada y en las provincias cercanas, y fundar con ellos dos poblaciones de 50 vecinos. Junto a la población introduciría también 1.000 vacas e igual número de puercos. Además, en un plazo no superior a los cuatro años, se comprometía a fundar el tercer asentamiento.

En la misma línea, el tesorero de Cumaná, Baltasar Pérez Bernal, solicitaba el gobierno de Cumaná por tres vidas y a cambio se ofrecía a hacer tres poblaciones de 50 vecinos, embarcando en el puerto sevillano 50 hombres, otros 150 en un plazo de 5 años, y reclutando 50 más de las provincias vecinas. También se comprometía a llevar armas, así como a descubrir ostiales y minas.

El comisionado no sólo no halló pruebas que culparan al onubense, sino que encontró mayores motivos para firmar cuanto antes la capitulación y que el gobernador partiese para el problemático territorio. Felipe II rubricó el documento con Francisco de Vides el 23 de marzo de 1592, apenas tres meses después de que el Consejo informara al rey favorablemente en este sentido. ${ }^{16}$

15 AGI, Indiferente, 741, N. $^{\circ} 276$. Informe...

16 Una copia de la capitulación puede verse en AGI, Caracas, 2. Libro de Nueva Andalucía, y otra en AGI, Contratación, 5235. 
El principal objetivo que se recoge en el documento es que Vides prosiguiera el "descubrimiento, pacificación y población" en Tierra Firme y comenzara el de los territorios insulares encomendados. La consecución de tal fin, y de acuerdo al ofrecimiento hecho previamente por Vides a la Corona, obligaba al firmante a transportar pobladores, armas y ganado, a su costa, en la flota de Tierra Firme, y con ellos fundar, de acuerdo con las normas existentes, al menos tres poblaciones. Vides llevaría consigo desde la metrópoli 200 hombres — 50 de ellos casados_-, algunos labradores, y 6 religiosos, y levantaría posteriormente en América otros 200 pobladores más. Fundaría la primera población en Puerto Píritu, con 80 vecinos y en el plazo de 3 meses, con el fin de preparar la entrada al Dorado; la segunda en la costa norte de Trinidad, con 150 casas y en el plazo de 6 meses; y la tercera en la provincia de Cumaná, con 80 vecinos, en el plazo de dos años, "sin que para esta ni las demás poblaciones hayais de sacar vecinos ni disminuyan las que al presente existen". La mitad del vecindario de estos centros estaría ya casado y Vides debería procurar que el resto también lo hiciera. Para el sustento y mejor desarrollo de las fundaciones se comprometía a introducir 1.000 vacas en el plazo de dos años: 300 para Puerto Píritu, 200 para Trinidad y las demás para la provincia de Cumaná y la nueva ciudad. Junto a estas reses metería 100 puercos, 100 yeguas, borricas, garañones y, por lo menos, 200 ovejas y cabras, animales que serían repartidos entre los pobladores.

En la realización de todo ello debía de gastar los 20.000 ducados que había ofrecido y llevar un libro de gastos donde quedaran reflejadas las partidas de egresos. A cambio de estas obligaciones, el monarca ofrecía las siguientes mercedes: el título de gobernador y capitán general por dos vidas, con un salario de 2.000 ducados anuales; posibilidad de encomendarse hasta 400 indios, así como conservar los que ya poseía en Venezuela, y de encomendar indios vacos a otras personas; facultad para realizar ciertos nombramientos; licencia para repartir tierras entre los pobladores; y facilidades para conseguir bastimentos a precios justos en la metrópoli, así como introducirlos en la gobernación por espacio de 10 años.

El título de gobernador, firmado algunos días después, ${ }^{17}$ era ya, por sí solo, una fuente de prerrogativas. Entre ellas cabe destacar el ejercicio de la justicia, tanto civil como criminal; recibir los derechos anejos al cargo;

17 AGI, Caracas, 2. Libro de Nueva Andalucía. Documento 141. Título de gobernador y capitán General, Madrid, 12 de abril de 1592. 
la orden de no poderle poner embargo "ni contradicción alguna"; y el privilegio de poder expulsar a las personas no gratas de la gobernación.

Estas capitulaciones son un documento de sumo interés para conocer el estado de la gobernación, las ambiciones de su primer mandatario y la política de la Corona. En ella quedan reflejados los problemas que acuciaban al territorio: la inestabilidad de sus escasos y pocos centros poblados, el corto número de cabezas de ganado, la amenaza indígena, la necesidad de defensa, así como los sueños que albergan los nuevos pobladores, es decir, la preocupación estratégica, la atracción que ejerce el Dorado, etc.

\section{Apresto de dos navios para el viaje de los colonizadores hacia la Nueva Andalucía}

Firmada la capitulación, comenzaron los preparativos para reunir a los 200 pobladores que acompañarían a Vides y para el apresto del navío en el que realizarían el viaje. La Corona - y el mismo Vides- deseaba que todo ello se desarrollase en el menor espacio de tiempo posible. El 12 de abril se dictó una real cédula que eximía al recién nombrado gobernador de arbolar bandera y de tocar instrumento alguno, para poder reclutar los pobladores con la mayor brevedad. Sólo se exigía que éstos se enviaran al puerto de Sanlúcar "ya divididos en forma de pobladores" para, una vez allí, ser alistados. ${ }^{18}$

A la Casa de Contratación se enviaron diversas órdenes. En unas se comunicaban las prerrogativas que tenía concedidas Vides y en otras se pedía al organismo sevillano que facilitase su salida. El 12 de abril se le ordenaba que, ya que había partido la flota de Tierra Firme, con la que estaba previsto que este contingente realizara la travesía, permitiese salir el navío en solitario o en conserva de la de Nueva España. ${ }^{19}$ Días después se volvía a informar de otra de las mercedes concedidas en la capitulación: que durante diez años podría enviar dos navíos en conserva de flota con bastimentos y cosas necesarias para la gobernación. ${ }^{20}$ Un mes después se notificaba que "atento a que la costa de la dicha provincia es de muchos bajíos" se había permitido que fuesen dos navíos de menor porte, en lugar de uno, no pudiendo exceder ninguno de los dos de las 120 toneladas. ${ }^{21}$ Por

18 Ibidem, doc. 142. Real cédula, Madrid, 12 de abril de 1592.

19 Ibidem, doc. 143. Real cédula a la Casa de Contratación, de igual fecha.

20 Ibidem, doc. 144. Real cédula a la Casa de Contratación. Madrid, 17 de abril de 1592.

21 Ibidem, doc. 147. Real cédula a la Casa de Contratación. El Pardo, 13 de mayo de 1592. 
último, a finales del mes de mayo se avisaba al organismo sevillano que Vides estaba eximido de llevar pilotos y maestre examinado, así como artillería, a causa de los gastos que de ello le seguirían. ${ }^{22}$

El 28 de agosto se hallaba todavía Vides en Sevilla, ultimando el despacho de sus dos navíos, cuando recibió de la Casa de Contratación la autorización de partida. En la documentación que tuvo que rendir el gobernador en el momento de su salida se encuentra la información acerca de las personas y avituallamiento que componían la expedición. En la anotación de los datos de estos pobladores no se hicieron las comprobaciones oportunas. Vides se excusó en este sentido alegando que procedían de provincias muy alejadas y que intentar ciertas averiguaciones retrasaría enormemente su marcha y, aunque es posible que no le faltase razón, lo es también que tratara de ocultar con ello lo mal provistos que iban sus hombres. ${ }^{23}$

\section{La expedición pobladora}

La lista completa de los pobladores estuvo ultimada el 13 de octubre, fecha en la que el gobernador firmó dos certificados — uno por cada barcocon los nombres, apellidos, lugar de origen de los pobladores, sus mujeres e hijos, así como del maestre que se hacía cargo de la embarcación. ${ }^{24}$

El onubense partió del puerto gaditano el 14 de noviembre y llegó a Cumaná el 18 del mes siguiente. ${ }^{25}$ En las embarcaciones "Nuestra Señora de la Concepción", a cargo del maestre Jaime de Rivas, y "Nuestra Señora del Rosario", del maestre Jorge Veneciano, el gobernador llevaba consigo "200 pobladores" que, en realidad, eran 286 personas, pues no se contabilizaban como tales las mujeres ni los hijos. De estas, 111 (hubieran sido 112, pero la mujer de uno de ellos murió antes de hacerlo) se embarcaron en la primera y 175 en la segunda.

22 Ibidem, doc. 148. Real cédula a la Casa de Contratación. San Lorenzo, 27 de mayo de 1592.

23 Ojer: La formación..., pág. 439.

24 En tres fuentes diferentes hemos podido encontrar la lista de estos pobladores. La que consideramos más fiable es la documentación contemporánea que se conserva en el Archivo de Indias, Contratación, 5235. Es un traslado de las reales cédulas, capitulación, y certificado de pobladores que Vides entregó a la Casa de Contratación para obtener la licencia. Este mismo expediente se encuentra transcrito en la Colección de documentos inéditos para la historia de Hispano-América, tomo IX, publicado por Luis Rubio Moreno: Pasajeros a Indias. Madrid, 1930. Por último, la lista también se encuentra en el Catálogo de pasajeros a Indias, vol. VII, 1586-1599, a cargo de M. a del Carmen Galbis Díez. Sin embargo, no sólo contiene algunos errores de transcripción sino que, además, está incompleta.

25 AGI, Escribanía, 1011 A, Pleitos, pieza n. ${ }^{\circ}$ 7. Vides al rey, Cumaná, 2 de enero de 1593. 
Con los datos aportados por la documentación podemos analizar el sexo, estado civil, lugar de origen y, en algunos casos, grado de estudio alcanzado y edad de los pobladores. De la totalidad de estos conocemos los dos primeros parámetros, y del 84,2\% también el lugar de origen. ${ }^{26}$

\section{Composición de la expedición}

El primer dato de interés que se desprende de los 286 acompañantes del gobernador es que eran mayoritariamente varones, adultos y solteros, $\mathrm{y}$ que los casados viajaban con sus esposas e hijos. Esto respondía a la nueva orientación de la Corona española, que tenía un objetivo claramente repoblador, y que no quería que se repitieran los desórdenes cometidos por los primeros conquistadores en América, entre los que se alcanzaron cifras muy altas de amancebamiento, bien por tener ya esposa en España, bien por no tener interés en contraer matrimonio. Es ya conocido como la incitación a la celebración de este sacramento en Indias había dado origen a un porcentaje significativo de personas que habiendo contraído nupcias en su lugar de origen, lo habían vuelto a hacer en los nuevos territorios, convirtiéndose éste en uno de los motivos de mayor persecución por parte del Santo Oficio. ${ }^{27}$

\section{CUADRO 1}

COMPOSICIÓN DE LA HUESTE

\begin{tabular}{llccc} 
& & N.S. Concepción & N.S. Rosario & Totales \\
\hline solteros & varones & 61 & 89 & 150 \\
\hline casados & marido & 20 & 30 & 99 \\
& mujer & 19 & 30 & \\
\hline \multirow{2}{*}{ hijos } & varones & 4 & 9 & 31 \\
& hembras & 5 & 13 & \\
\hline clérigos & & 2 & 4 & 6
\end{tabular}

26 En realidad 254 aparecen con su lugar de origen, pero en 13 casos (el 4'5\%), no hemos podido determinar con exactitud la población a la que se refieren. El resto, es decir 32 pobladores, no presentan datos pero, al tratarse de los hijos, presuponemos que en su mayor parte serían del mismo que sus padres. Esto reforzaría aún más el valor de los datos obtenidos con sus progenitores.

27 Ver Gómez Pérez y Marchena Fernández: "Los señores ...”; y Marchena Fernández: "Los hijos de ...". 
Efectivamente, un 89'9\% eran adultos. De éstos, algo más de la mitad, es decir 150, estaban solteros (un 58'8\%), 50 viajaban con sus respectivas mujeres (uno es el que había quedado viudo justo antes de embarcar) y 6 vestían los hábitos religiosos. De las 50 parejas (contando como tal también la del viudo), 17 viajaban con sus hijos menores, con una media de hijos por pareja en torno a los 1' 8 , y una media de edad que rondaba los 6 años y medio. Es de señalar igualmente que las edades de los hijos abarcaban desde los 19 años a los 2 meses, y que eran mayoritariamente niñas (58\%).

Entre las huestes de conquistadores-pobladores de la primera mitad de siglo, y la de Vides, de 1592, existen ya claras diferencias. El hecho de que un $10 \%$ de los emigrantes sean menores, una cuarta parte de los varones viajen con sus mujeres, y que el 23 ' $4 \%$ del total sean mujeres y niñas, indica claramente cual es la orientación pobladora de la Corona.

\section{Origen de los pobladores}

De acuerdo con los datos relativos a su lugar de origen, podemos afirmar que casi la totalidad de los pobladores eran castellanos. Entre ellos destaca la Andalucía occidental, Extremadura y algunas provincias del centro peninsular, lo que parece no alejarse de las cifras obtenidas por BoydBowman para la primera mitad de siglo. ${ }^{28}$ Se puede destacar, casi como anecdótica, la presencia de algunos valencianos, cántabros, gallegos y asturianos, así como la simbólica de un par de murcianos y canarios, un catalán, un vasco, un riojano y un gascón. Al grupo más importante nos referiremos a continuación.

Los acompañantes de Vides procedentes de tierras andaluzas y extremeñas son, sin duda, los más numerosos. El 36'9\% obtenido para los andaluces es similar a las cifras de Boyd-Bowman, aunque el $24 \%$ de los extremeños es claramente superior. Hay que remontarse a las huestes de los grandes conquistadores para encontrar tal proporción de extremeños. La razón resulta obvia. El propio gobernador procedía de la zona más oriental de Andalucía, casi vecina con Extremadura, lo que habría favorecido la incorporación de estos.

28 Boyd-Bowman, Peter: Índice geobiográfico de 40.000 pobladores españoles en el s. XVI. T. I, Bogotá, 1964; T. II, México, 1968; "La procedencia de los españoles de América, 1540-1559", Historia Mexicana, vol. 17, n. ${ }^{\circ}$ 65. México, 1967; "La emigración española a América, 1560-1579”, Studia Hispanica in Honorem R. Lapesa, T. II. Madrid, 1974; y "Patterns of Spanish Emigration to the New World, 1493-1580", The Americas, vol. XXXIII, n. ${ }^{\circ}$ 1. Washington, 1976. 
En Andalucía, más que en el resto del territorio peninsular, resulta indispensable analizar los datos con mayor detenimiento porque de sus ocho provincias, sólo dos - Sevilla y Huelva- aportaron las tres cuartas partes del total y, si distinguimos entre la Alta y Baja Andalucía, obtendremos el dato de que de la primera sólo salieron un 11 '2\%, mientras que de la segunda lo hicieron el 88'7. Las provincias que mayor número aportaron fueron, en orden descendente, Badajoz, Sevilla, Huelva y Cáceres. Y de ellas es necesario destacar que en Sevilla capital se enroló el mayor contingente poblador.

CUADRO 2

ORIGEN DE LOS POBLADORES. PORCENTAJE POR REGIONES

\begin{tabular}{lcc} 
& Número & $\%$ \\
\hline Andalucía & 89 & $36^{\prime} 9$ \\
Extremadura & 58 & $24^{\prime} 0$ \\
Castilla & 48 & $19^{\prime} 9$ \\
León & 17 & $7^{\prime} 0$ \\
Cataluña & 1 & $0^{\prime} 4$ \\
Valencia & 7 & $2^{\prime} 9$ \\
Murcia & 2 & $0^{\prime} 8$ \\
País Vasco & 1 & $0^{\prime} 4$ \\
Rioja & 1 & $0^{\prime} 4$ \\
Cantabria & 6 & $2^{\prime} 4$ \\
Asturias & 4 & $1^{\prime} 6$ \\
Galicia & 4 & $1^{\prime} 6$ \\
Canarias & 2 & $0^{\prime} 8$ \\
Francia & 1 & $0^{\prime} 4$ \\
\hline ToTAL & 241 &
\end{tabular}

El peso de Andalucía, como afirma Solano, ${ }^{29}$ fue notable. El porcentaje es similar al ofrecido en su trabajo: uno de cada tres pobladores embarcados con Vides era andaluz. Lo que hace variar a esta expedición

29 Solano, Francisco de: "El conquistador hispano: señas de identidad", en Proceso histórico al conquistador. Madrid, 1988, pág. 21. 
M. ${ }^{a}$ JOSÉ NESTARES PLEGUEZUELO

CuAdro 3

POBLADORES DE ORIGEN ANDALUZ

\begin{tabular}{|c|c|c|c|c|}
\hline Provincia & Localidad & & Total & $\%$ \\
\hline ALMERÍA & Almería & 2 & 2 & 2’2 \\
\hline \multirow[t]{3}{*}{ CÁDIZ } & Gibraltar & 2 & 6 & $6 ’ 7$ \\
\hline & Jerez & 2 & & \\
\hline & Villamartín & 2 & & \\
\hline \multirow[t]{4}{*}{ CÓRDOBA } & Bujalance & 2 & 7 & $7 ’ 9$ \\
\hline & Córdoba & 1 & & \\
\hline & Espejo & 1 & & \\
\hline & Lucena & 3 & & \\
\hline GRANADA & Granada & 2 & 2 & 2’3 \\
\hline \multirow[t]{8}{*}{ HuElVA } & Aracena & 5 & 26 & $29^{\prime} 2$ \\
\hline & Ayamonte & 2 & & \\
\hline & Beas & 5 & & \\
\hline & Hinojales & 1 & & \\
\hline & Moguer & 2 & & \\
\hline & Niebla & 1 & & \\
\hline & Trigueros & 8 & & \\
\hline & Villarrasa & 2 & & \\
\hline \multirow[t]{3}{*}{ JAÉN } & Jaén & 1 & 3 & $3{ }^{\prime} 4$ \\
\hline & Bailén & 1 & & \\
\hline & Úbeda & 1 & & \\
\hline \multirow[t]{2}{*}{ MÁlAGA } & Málaga & 1 & 3 & $3^{\prime} 4$ \\
\hline & Antequera & 2 & & \\
\hline \multirow[t]{8}{*}{ SEvilLa } & Sevilla & 28 & 40 & $44^{\prime} 9$ \\
\hline & Camas & 1 & & \\
\hline & Carmona & 2 & & \\
\hline & Ecija & 2 & & \\
\hline & Estepa & 2 & & \\
\hline & Huévar & 1 & & \\
\hline & Osuna & 1 & & \\
\hline & Triana & 3 & & \\
\hline
\end{tabular}


de los datos globales para el siglo XVI, fue la menor participación sevillana. Si la tónica general indica que uno de cada cinco procedían de esta provincia andaluza, y uno de cada seis de la capital, con Vides sólo lo hicieron uno de cada seis en el primer caso y uno de cada ocho en el siguiente. La causa radica en la mayor importancia de la provincia de Huelva en esta emigración.

A Sevilla le siguieron Fuente de Cantos, en el término de Badajoz, y Brozas, en el de Cáceres. No pueden dejar de citarse tampoco los 10 pobladores procedentes de Mérida, en Badajoz, y los 8 de Trigueros — uno de ellos el propio gobernador-. Algunas de estas pequeñas poblaciones debieron sufrir un importante esquilmo en su población. De Fuente de Cantos, por ejemplo, salieron 8 familias más 8 varones solteros. Es curioso, incluso, si uno se detiene en el análisis de los apellidos, comprobar que gran parte de ellos estaban emparentados entre sí. Las redes familiares se extendían, incluso, a varias poblaciones cercanas. Entre los naturales de Mérida, por ejemplo, encontramos parentesco con los de Fuente de Cantos. Parece ser que la posibilidad de viajar junto a personas de la misma sangre animaba a la aventura de dejar sus paupérrimas tierras y buscar mejor fortuna en un nuevo territorio que, aunque lejano, ofrecía aún el espejismo del famoso Dorado.

\section{CUAdRo 4}

POBLADORES DE ORIGEN EXTREMEÑO

\begin{tabular}{llrcc} 
Provincia & Localidad & & Total & $\%$ \\
\hline BADAJOZ & Don Benito & 1 & 41 & $70{ }^{\prime} 7$ \\
& Fregenal & 1 & & \\
& Fuente de Cantos & 22 & & \\
& Jerez de los Caballeros & 2 & & \\
& Llerena & 2 & & \\
& Mérida & 10 & & \\
& Villanueva de la Serena & 1 & & \\
& Zafra & 2 & & \\
\hline CÁCERES & Alcántara & 1 & 17 & $29{ }^{\prime} 3$ \\
& Brozas & 13 & & \\
& Garrovillas & 1 & & \\
& Trujillo & 1 & & \\
& Valencia de Alcántara & 1 & &
\end{tabular}


M. ${ }^{a}$ JOSÉ NESTARES PLEGUEZUELO

CuAdRo 5

POBLADORES CASTELLANO-LEONESES

\begin{tabular}{|c|c|c|c|c|}
\hline Región & Provincia & Localidad & & Total \\
\hline \multirow[t]{24}{*}{ Castilla } & Avila & Arévalo & 1 & 1 \\
\hline & Burgos & Briviesca & 1 & 1 \\
\hline & \multirow{2}{*}{ Guadalajara } & Mondéjar & 1 & \multirow{2}{*}{5} \\
\hline & & Tendilla & 4 & \\
\hline & \multirow[t]{6}{*}{ Madrid } & Madrid & 5 & \multirow[t]{6}{*}{15} \\
\hline & & Alcalá de Henares & 1 & \\
\hline & & Alcobendas & 1 & \\
\hline & & Barajas & 2 & \\
\hline & & Ciempozuelos & 4 & \\
\hline & & Getafe & 2 & \\
\hline & \multirow[t]{2}{*}{ Palencia } & Palencia & 1 & \multirow[t]{2}{*}{2} \\
\hline & & Aguil. Campo & 1 & \\
\hline & \multirow[t]{2}{*}{ Segovia } & Cúellar & 1 & \multirow[t]{2}{*}{2} \\
\hline & & Villacastín & 1 & \\
\hline & \multirow[t]{2}{*}{ Soria } & Bleza & 1 & \multirow[t]{2}{*}{2} \\
\hline & & Burgo de Osma & 1 & \\
\hline & \multirow[t]{4}{*}{ Toledo } & Toledo & 7 & \multirow[t]{4}{*}{14} \\
\hline & & Consuegra & 3 & \\
\hline & & Mora & 1 & \\
\hline & & Talavera & 3 & \\
\hline & \multirow[t]{4}{*}{ Valladolid } & Valladolid & 2 & \multirow[t]{4}{*}{5} \\
\hline & & Medina del Campo & 1 & \\
\hline & & Peñafiel & 1 & \\
\hline & & Tordesillas & 1 & \\
\hline \multirow[t]{6}{*}{ LEÓN } & \multirow[t]{4}{*}{ Salamanca } & Salamanca & 1 & \multirow[t]{4}{*}{7} \\
\hline & & Los Santos & 1 & \\
\hline & & Peñaranda & 1 & \\
\hline & & Vitigudino & 4 & \\
\hline & \multirow[t]{2}{*}{ Zamora } & Zamora & 6 & \multirow[t]{2}{*}{10} \\
\hline & & Santovenia & 4 & \\
\hline
\end{tabular}


De la zona castellano-leonesa se alistaron 65 personas, mayor número que de la extremeña pero de menor importancia relativa, teniendo en cuenta el amplio espacio geográfico que comprende. Con todo, resulta indispensable destacar la aportación de provincias como Madrid, Toledo y Zamora. La villa de Madrid y sus alrededores -Alcobendas, Barajas, Ciempozuelos, Getafe y Alcalá de Henares- contribuyeron con 15 pobladores. La ciudad de Zamora y Santovenia, con 10, y Toledo capital con 7 más.

El resto de los pobladores que acompañaron a Vides, es decir el 12\%, procedían de diferentes puntos del norte, levante y territorios insulares de la Corona española. Aunque muy diseminados, pueden destacarse los 7 valencianos, y los 4 de Castro Urdiales, en Cantabria.

\section{CuAdro 6}

POBLADORES DEL NORTE Y LEVANTE ESPAÑOL. OTROS ORÍGENES

\begin{tabular}{llllc} 
Región & Provincia & Localidad & & Total \\
\hline \multirow{2}{*}{ GALICIA } & Lugo & Castro & 1 & 1 \\
\cline { 2 - 5 } & Pontevedra & Pontevedra & 2 & 3 \\
& & Bayona & 1 & \\
\hline \multirow{2}{*}{ ASTURIAS } & & Gijón & 2 & 4 \\
& & Luarca & 1 & \\
& & Navia & 1 & \\
\hline CANTABRIA & & Castro Urdiales & 4 & 6 \\
& & Santander & 2 & \\
\hline PAís VASCO & Guipuzcoa & Oñate & 1 & 1 \\
\hline CATALUÑa & Lérida & Cervera & 1 & 1 \\
\hline VALENCIA & Castellón & Almenara & 1 & 1 \\
& Valencia & Valencia & 6 & 6 \\
\hline MURCIA & & Yecla & 1 & 2 \\
& & El Peral & 1 & \\
\hline CANARIAS & Canarias & Canarias & 1 & 2 \\
& & Tenerife & 1 & \\
\hline FRANCIA & & Gascuña & 1 & 1
\end{tabular}


Una última consideración acerca de la composición social de la expedición pobladora nos permite afirmar, siguiendo a Pietschmann,$^{30}$ que el grupo era un reflejo de la sociedad peninsular, a caballo entre el feudalismo y el incipiente capitalismo, y que se enmarcaba dentro de los parámetros pobladores establecidos por la Corona. En la expedición no se incluyeron ni la rancia nobleza ni la moderna burguesía. Hacia Venezuela no se trasladaron, por tanto, ni clases privilegiadas, ni las nuevas clases económicas que pujaban por hacer de América un precioso mercado. Se trataba, únicamente, de colonizar un territorio para ponerlo bajo la bandera del Imperio, y de impedir que en él se repitieran los abusos sociales que existían en la Península.

\section{Vides en la región de Cumanagotos}

Francisco de Vides llegó en diciembre de 1592 a una gobernación que sólo contaba con una provincia, la de Cumaná, y dos ciudades de españoles, Cumaná y Nueva Ecija de los Cumanagotos. La mayor de ellas, Cumaná, que era la capital, tenía 200 habitantes. La realidad era, por tanto, compleja y el trabajo por realizar ingente.

Tal y como rezaba su capitulación, su primer objetivo debía dirigirse en dirección oeste, hacia la zona que habitaban los cumanagotos. Uno de los primeros actos de su gobierno fue el de enviar a 100 de los 200 pobladores que había traído consigo hacia la ciudad de la Nueva Ecija ${ }^{31}$ De forma paralela, Vides había organizado dos expediciones. La primera, a cargo de Gerónimo de Campos, se dirigiría hacia los llanos del interior, en busca del Dorado. La otra, a cuya cabeza marcharía él personalmente, tendría un objetivo eminentemente poblador.

A pesar de haber escrito a la Corona en enero de 1593, anunciando que se encaminaba hacia la zona occidental, no fue hasta 1594 cuando tenemos certeza de su llegada. De acuerdo con Ojer, ${ }^{32}$ Vides buscaba el sitio más a propósito para la fundación de su primera ciudad, y el lugar denominado por los indígenas "aripata" le pareció el más conveniente por

30 Pietschmann: El Estado ..., págs. 51-52.

31 AGI, Escribanía de Cámara, 1011 A, Pleitos. Francisco de Vides al rey, Cumaná, 2 de enero de 1593. También se puede consultar la descripción que hace el padre fray Antonio Caulín sobre esta primera intervención de Vides en Historia de la Nueva Andalucía. Caracas, 1966, págs. 285-286.

32 Ojer, Pablo: "Una ciudad inédita. Nuestra Señora de Clarines", El Farol, n. ${ }^{\circ}$ 177. Caracas, 1957, pág. 14. 
hallarse junto al río Unare. ${ }^{33} \mathrm{El}$ emplazamiento no debió estar muy lejos de la actual localidad de Clarines, a una cuantas leguas tierra adentro, con un claro sentido estratégico: aprovechar el río como vía de comunicación, resguardarse de los ataques por la costa y preparar las entradas hacia las tierras del interior.

La ciudad fue fundada el 7 de abril con el nombre de Nuestra Señora de Clarines, con 60 vecinos. Para los primeros cargos de la población, de acuerdo con el acta de fundación estudiada por el padre Ojer, ${ }^{34}$ fueron escogidos algunos de los pobladores que acompañaron a Vides. Lorenzo García de Castilla, procedente de Fuente de Cantos, fue nombrado regidor; Bartolomé Hernández, de Almenara (Castellón), alcalde de Santa Hermandad; y Juan Rodríguez, pontevedrés, procurador general.

Apenas dos años más tarde, el gobernador envió a su teniente, el capitán Lucas Fajardo, hacia esta zona, para fundar una nueva ciudad, en una posición intermedia entre la de Clarines y Cumaná. El lugar elegido sería la ribera del río Guatapanare o Salado, no lejos de la margen derecha del Neverí, en el que actualmente ocupa la localidad de Pozuelos, vecina de la de Barcelona ${ }^{35}$ En realidad, más que de una fundación, se trataba de la reunión y traslado de las dos pequeñas poblaciones existentes - Nueva Ecija de los Cumanagotos y Nuestra Señora de Clarines-, a una posición más oriental. Con ello, Vides perseguía varios propósitos. De un lado formaba una ciudad algo mayor que las dos anteriores, que sobrevivían en una situación muy precaria, y, de otro, sumaba a su curriculum una fundación.

En una carta remitida al monarca en abril de 1596 se argumentaba que la población de Clarines había disminuido tanto, que para librar a los que quedaban del peligro indígena se había decidido incorporarlos a la ciudad de Cumanagotos..$^{36}$ La ciudad debió quedar abandonada entre marzo y mayo de este año. ${ }^{37}$

La nueva fundación, llamada Nueva Frechilla de San Cristóbal de Clarines, no resultó muy acertada. A muchos pobladores les disgustó la actitud tiránica del gobernador al obligarles a salir de los anteriores empla-

33 AGI, Santo Domingo, 15, n. ${ }^{\circ} 25$. Declaración de testigos ante el gobernador de Venezuela, Caracas, 20 de marzo de 1597. Testimonio de Gaspar de Torres y de Esteban Lorenzo.

34 AGI, Escribanía de Cámara, 1011A, Pleitos. Testimonio del Acta de Fundación terminado por el escribano Francisco López de Uquillas, 9 de abril de 1594.

35 Ibídem. Testimonio de la población, Nueva Frechilla, 3 de abril de 1596. de 1596.

36 AGI, Santo Domingo, 191. Roque de Montes Colmenares al rey, Cumaná, 18 de abril

37 AGI, Santo Domingo, 15. Declaración de testigos... 
zamientos. Este malestar, unido al desabastecimiento con que continuaron sobreviviendo en la nueva población, al no facilitarles Vides los recursos básicos a los que se había comprometido, animó a muchos de ellos a huir a las vecinas provincias de Caracas y Margarita, que les recibían con los brazos abiertos. Recordemos que todo poblador estaba obligado a no separarse del jefe, sin licencia, bajo pena de muerte ${ }^{38}$ y aunque Vides consentía con la venta de estas licencias, los paupérrimos habitantes optaron por el recurso de la fuga.

Desde su fundación, el procurador de la ciudad, Gaspar de la Esquina, había trabajado afanosamente para dotarla de medios y asegurar así su supervivencia. Sus desvelos tuvieron su recompensa en agosto del año siguiente cuando por diversas reales cédulas la ciudad obtuvo de la Corona armas, municiones, vino, aceite, ornamentos y contribuciones de la Real Hacienda para la fábrica de la iglesia. ${ }^{39}$ Sin embargo, desde hacía tiempo la huída de sus habitantes se había convertido en uno de los mas serios inconvenientes para la continuidad de la fundación. Una de esas reales cédulas instaba al gobernador a que señalara un breve plazo a los desertores para volver a la ciudad.

Pero el mandatario cumanés, en la fecha en que se recibieron estas órdenes reales ya había sido cesado. Como consecuencia de las acusaciones vertidas contra su persona, fundamentalmente por las contenidas en la información levantada por el gobernador de Venezuela en marzo de ese año, se había dictado el 9 de julio la destitución, y pocos meses después se procedió a someterlo a juicio de residencia.

\section{Acusaciones de antiguos pobladores contra Vides}

Once fueron los testigos que declararon bajo juramento ante el gobernador de Venezuela Diego de Osorio. ${ }^{40}$ Esteban Lorenzo, de 26 años, y Juan Pascual, de 24 o 25, eran vecinos de la Nueva Ecija cuando llegó la expedición. Francisco Marín, de 25, llegó a la gobernación poco después que el nuevo gobernador. El resto era parte de la expedición trasatlántica. Domingo de Santamaría, de 37, y Andrés de Sotomayor, de 44, eran vallisoletanos y habían llegado con su mujer e hijos a Cumaná en el navío

38 Solano: "El conquistador ...”, pág. 20.

39 AGI, Caracas, 2. Libro Nueva Andalucía, docs. 217-221. Reales cédulas de agosto de 1597.

40 AGI, Santo Domingo, 15. Declaración de testigos... 
"Nuestra Señora del Rosario". Miguel de la Cuesta, de 22 años, era uno de los solteros que también había viajado en ese barco. Cristóbal Rodríguez de Orihuela procedía de Beas de Huelva, tenía 30 años, y había venido a las Indias con su mujer e hijos en la misma embarcación que Vides. Pedro de Menyugo, de 24, procedente de Santo Domingo de la Calzada, en Logroño, y Gaspar de Torres, de 30, natural de Salinas de Guadiana, también venían en el mismo barco. Los dos restantes - Juan de Ariño, de 24, y Francisco Moreno, de 50- habían sido igualmente soldados a las órdenes de Vides. En el momento de la declaración todos ellos estaban ya avecindados en la ciudad de Caracas. Los once testigos "dolos" fueron interrogados en torno al asunto que se seguía contra Vides, y todos ellos ofrecieron respuestas similares.

\section{Irregularidades en el viaje desde Sanlúcar}

De acuerdo con las declaraciones de estos antiguos pobladores, en el viaje realizado desde Sanlúcar de Barrameda hacia el nuevo destino, Vides había cometido numerosas irregularidades. Unas afectaban directamente a la Corona y otras personalmente a los colonizadores.

La Corona debía sentirse afectada porque el triguereño sólo había llevado 100 de los 200 pobladores estipulados en la capitulación, con una cifra de casados entre 15 y 22 - pudiendo, según ellos, tratarse en algún caso de amancebamiento- y con un único clérigo, "un tal Perdomo". ${ }^{41} \mathrm{La}$ composición y las armas que estos llevaban también se había falseado. A falta de soldados, Vides anotó como tales a ciertos pasajeros. Domingo de Santamaría confiesa ser uno de ellos. Los barcos tampoco llevaban las armas preceptivas. Casi todos los soldados tenían espada y daga, pero sólo algunos poseían escopeta, y eso porque, según denunciaba Sotomayor, el gobernador les había obligado a comprarlas.

Junto al engaño que el onubense causaba a la Corona con el número de pasajeros, y la indefensión de la expedición, ellos se sentían afectados por el trato recibido. Por la capitulación firmada, Vides se había comprometido a correr con los gastos del transporte de los pobladores pero, no sólo había cobrado el flete a un gran número de ellos, sino que les había arre-

41 A pesar de la unanimidad de las declaraciones, en este punto es muy posible que los acusadores no llevasen razón. La documentación contemporánea parece estar del lado de Vides y, por tanto, de que llevó los 200 pobladores que declaró en su informe antes de partir del puerto gaditano. 
batado su matalotaje, haciéndoles pasar hambre y había llegado aún más lejos: alimentó a la tripulación con los avituallamientos de los pasajeros, racionó en exceso la comida, provocando hambre, y vendió la sobrante al llegar a Cumaná. Andrés de Sotomayor se aventuró incluso a calcular las raciones: cada pasajero había metido un quintal de bizcocho para sí, y Vides no les entregó sino una libra diaria, y eso "que no les dio ración treinta días cabales".

El viaje tampoco había resultado confortable. Algunos soldados estuvieron "desacomodados" en beneficio de unos mercaderes y otros pasajeros que habían pagado su flete. Sobre el precio que los colonizadores habían pagado al gobernador, bien por el viaje, bien por la obtención de una licencia a la llegada para abandonar la gobernación, los testigos ofrecieron numerosos testimonios. De ellos se deduce que a la salida del puerto andaluz, y para costear el pase por su conflictiva barra, les cobró 4 reales a cada uno, o bien ciertas prendas a los que no dispusieron de tal cantidad. Por el flete había exigido entre 10 y 50 pesos, según las posibilidades del que tenía que abonarlos. También en este caso admitió cantidades en especie, normalmente en forma de tabaco. Sobre los pagos recibidos en concepto de licencia hay menos ejemplos. Hubo un caso de 100 pesos y otro en que la otorgó a cambio de una escopeta. Y, según estos antiguos pobladores, Vides no había hecho más que comenzar con sus sucios y falsos negocios. ${ }^{42}$

\section{Críticas a la actividad pobladora. Fundaciones y causas de la despoblación}

La actividad pobladora de Vides no recibió menores críticas. Todos admitieron que llegó a fundar la población de Clarines en la región de los cumanagotos, aunque no exactamente en Puerto Píritu, sino "cuatro leguas más adentro, en el río Unare", y más de un año después del plazo señalado. Sin embargo le acusaron de haber falseado la fundación, ya que se trató de una simple mudanza de lugar y nombre, con el agravante de haberla realizado a la fuerza y con la oposición de sus vecinos. Marín llegó a afirmar que "la despobló contra la voluntad de los pobladores, con los que anduvo a mojicones sobre ello hasta la despobló y la mudó", y Cuesta recordó los desprecios que sufrieron, como cuando llegó a recriminarles que aquello no

42 AGI, Santo Domingo, 15. Declaración de testigos... 
era una ciudad sino una ranchería. Todos concordaron al afirmar que muchos de los habitantes de la Nueva Écija huyeron con posterioridad.

Los testigos también se complacieron en reseñar que poco después se despobló, culpando única y directamente al triguereño. Uno de ellos apuntaba que fue "por estar en mal sitio, por peligro de indios, por enfermedad y por hambre" y otro "a causa de no mandar enviar el socorro que le pidieron". Sólo un testigo hace mención del compromiso de Vides respecto a la fundación en Trinidad, y Domingo de Santamaría lo acusó de no haber realizado ninguna población a causa de su enfrentamiento con Antonio de Berrío.

El resto sí menciona el hecho de que no había levantado ninguna población en Cumaná, ni en la costa, y todos se aventuran a asegurar que tampoco tendría ocasión de hacerlo "a causa de no tener gente para ello", porque no quería "hacer gasto con los soldados", ni tampoco "gana de ello". Pero la principal causa que motivó las huidas de los colonizadores, y por tanto el fracaso de los asentamientos, parece ser el desabastecimiento con que el gobernador castigó a las fundaciones.

El mandatario cumanés no sólo no los abasteció con el ganado que se había comprometido en su capitulación, sino que utilizó un ardid para justificarse ante la Corona que encendió aún más la cólera de los pobladores. El subterfugio consistió en la introducción de 200 o 300 vacas en Clarines, para llevárselas días más tarde, una vez recogido el testimonio de la entrada. No repartió ninguna vaca, cerdo, oveja, o cabra entre los pobladores. Sólo dejó allí, para el consumo, las que pudieron pagarle. Los vecinos debieron quedar, de acuerdo con el ímpetu que colorea sus acusaciones, con un sentimiento a medias entre la rabia y la desolación. Habían esperado el ganado para saciar su hambre, y poder prosperar con la economía ganadera pero, no sólo no lo habían conseguido, sino que se sentían burlados. Unos, como Sotomayor, señalaban que se lo había llevado a Cumaná para venderlo "porque Vides oyó decir que le habían de valer más de 12.000 ducados" y otros que no era suyo. Miguel de la Cuesta afirmaba que era de un tal Trujillo, que se lo había dado a cambio de la vara de alguacil, y, tanto Orihuela como Moreno, que pertenecía a un tal Hernando de Chaves.

El único abastecimiento que se dignó ofrecer fue el maíz, y para ello no sólo había utilizado los mismos falsos procedimientos de siempre, sino que la cantidad que entregó fue irrisoria. Menguyo dijo que "no les daría sino solamente una fanega de maíz para cada mes y si hasta daba era lo que 
vendía a los soldados". Cuando en una ocasión Miguel de la Cuesta le pidió "un poco de maíz, le maltrató y le dijo que se fuese a Castilla". A Orihuela en la misma circunstancia le contestó que se alimentara de raíces.

Vides, sin embargo, de todo conseguía testimonios a su favor. Se valía de ciertas tretas para hacer pasar una venta por donación. Abonó con ciertas cantidades de lienzo a unos soldados el trabajo realizado a cambio de que éstos firmaran que se les había dado de forma graciosa. Por otro lado, cuando un soldado necesitaba de este tejido y no se le debía nada, el onubense se cobraba en gallinas.

En el surtimiento a sus soldados, Vides actuó como un auténtico mercader. Les vendía "a excesivos precios" y les llevaba, a cambio, sus pobrezas. Miguel de la Cuesta cita como ejemplo que él le había comprado en 25 pesos un vestido que al gobernador le había costado 9.

Los habitantes de Clarines, abandonados como se sentían, y en situación muy precaria, lucharon por su continuidad. El Cabildo de la ciudad comisionó al alcalde, Bartolomé de Almenara, para que se presentara ante Vides en solicitud de socorros, pero el extremeño solo consiguió que el gobernador lo enviara a prisión y calificara a los pobladores de "bellacos, comilones, destruidores de sus gobernadores y capitanes". ${ }^{43}$

Junto al abandono con el que estaba sentenciando la continuidad de la población, la máxima autoridad civil era responsable de otro grave problema que amenazaba a su población: los ataques indígenas. Los naturales recelaban de estos españoles a causa de que la expedición encabezada en 1593 por Gerónimo de Campos, había intentado paliar su fracaso con el rescate de varios indios, algunos de los cuales fueron entregados como esclavos a la esposa del gobernador, Elvira de Montes.

\section{El carácter del gobernador como causa de despoblación}

Por encima de las adversidades, lo que más pareció incomodar a los vecinos fue la actitud de su gobernador. El trato dispensado a los soldados y pobladores parece ser el principal motivo que argumentaban para justificar su huída. Todos recogen en sus declaraciones que era "insufrible", que los trataba mal "de palabra y de obra", que "usaba de demasías e términos tan malos que fue causa para lo dejar solo". Sotomayor llega a decir que "con los vecinos y soldados es de mala condición y les toma sus haciendas

43 Ibidem. Testimonio de Juan Pascual. 
y así se van huyendo a la Margarita". Por lo demás, también concuerdan en afirmar que con un trato más cuidadoso no sólo no se habrían marchado, sino que incluso hubiera recibido efectivos de fuera de la gobernación. Santamaría se lamentaba de que "si tuviera condición afable y acariciara a los soldados no se le hubieran ido, y de cada día vinieran a su gobierno otras personas de otros lugares por donde se viera ocasión de acrecentarse la gobernación con pueblos que se poblase".

El suceso que parece haber afectado con mayor intensidad a los antiguos pobladores de Vides fue su decisión de trasladar Nueva Ecija. Según los relatos de los testigos, el gobernador había encontrado 60 ó 70 hombres baquianos y de guerra en aquella fundación, debiéndose limitar su función a socorrerlos con algunos pobladores, bastimentos y armas, pero Vides no sólo no los socorrió con lo más necesario, sino que los obligó a trasladarse a un nuevo emplazamiento. En sus declaraciones los testigos recordaron con rabia cómo el gobernador les había expulsado de la población y cómo algunos de ellos habían decidido por ello abandonar la gobernación.

La principal consecuencia, por tanto, de la fundación de Clarines fue la importante pérdida de efectivos humanos para la gobernación. El desabastecimiento con que continuó castigando a la nueva ciudad, así como el mal trato dispensado durante los dos años que subsistió, fue un nuevo aliciente para la huída de otro grupo de pobladores. Esto, unido a que no intentó reclutar en las vecinas gobernaciones los 200 pobladores a que se había comprometido, significó que los efectivos humanos a finales de 1596 y principios de 1597 eran muy escasos. Sus acusadores apenas si contabilizaban entre 8 y 20 pobladores con los que emprender las siguientes fundaciones.

A pesar de que las declaraciones de los testigos pudieran estar animadas por la cercanía de los acontecimientos, lo que sí parece cierto es que Vides debió tener un carácter insufrible y que gobernó tiránicamente en Cumaná, enfrentándose, despreciando y vilipendiando a las autoridades no sólo locales sino incluso a las que se enviaron desde la Audiencia de Santo Domingo.

No vamos a entrar aquí en las polémicas que levantó su actuación al frente de la gobernación, ni su enfrentamiento con el gobernador Antonio de Berrío, ya que desviaría nuestra atención del aspecto que nos ocupa, pero sí cabe destacar que fue esa actitud la que dio al traste con sus ambiciones pobladoras. Sus pobladores actuarían como testigos en contra suya y la justicia dominicana se mostraría especialmente firme con una persona que tantas veces la había despreciado. 


\section{Destitución y proceso contra el gobernador}

A pesar de que fue la información de testigos levantada por el gobernador de Venezuela la que dio curso a la destitución el 9 de julio de 1597, eran numerosas las personas e instituciones que la habían estado preparando desde poco tiempo después de su llegada al territorio neoandaluz. ${ }^{44}$

Antonio Silveira de la Cerda que, recordemos, era sobrino de Núñez Lobo, había presentado a principios de 1594 una memoria en la Audiencia de Santo Domingo en la que trataba de probar que no había cumplido con lo capitulado. ${ }^{45}$ Por su parte, el fiscal del tribunal dominicano, abiertamente contrario a la actuación del triguereño, había agregado a las acusaciones mencionadas la de estar implicado en negocios de contrabando y la de estar obstaculizando la comunicación de los vecinos de su gobernación con la Audiencia, porque interceptaba la correspondencia. ${ }^{46}$

El tribunal dominicano puso en marcha diversas averiguaciones, que si bien iban a encontrarse con numerosos obstáculos, terminarían consiguiendo la destitución y encarcelamiento del acusado. En marzo de 1594 se comisionó a Pedro de Arce que comprobase la veracidad de los cargos imputados por Silveira y el fiscal de la Audiencia, ya que tenía a su cargo otras causas relativas a funcionarios y autoridades cumaneses, y, paralelamente, se confió al madrileño Ventura Maldonado Matute un importante cuerpo de causas, entre las que destacaban una contra Vides por incumplimiento de la capitulación y otra por el embargo impuesto por el gobernador contra Silveira de la Cerda. ${ }^{47}$

Maldonado abrió un juicio contra Vides en la isla Margarita en junio de 1595. Poco después tuvo que suspenderlo por motivos ajenos al caso, pero antes de pasar a Cumaná tuvo tiempo de levantar una información de testigos contra Vides. ${ }^{48} \mathrm{El} \mathrm{juez} \mathrm{sabía} \mathrm{que} \mathrm{su} \mathrm{comisión} \mathrm{no} \mathrm{iba} \mathrm{a} \mathrm{ser} \mathrm{sencilla.}$ Vides había provocado vergonzosos incidentes incluso ante la decisión del obispo de Puerto Rico de cursar una pesquisa religiosa. Los habitantes de la gobernación estaban tan asustados que no se atrevieron a colaborar en

44 Sobre la destitución, Joaquín A. Ramírez (Las primeras familias de Caracas, Caracas, 1986), señala que la destitución se produjo el 9 de julio de 1597 como consecuencia de la actuación del gobernador de Venezuela y Pablo Ojer (La formación...), señala que el 2 de marzo de 1598 el rey designó a Diego de Prado para acometer el juicio de residencia y que fue éste quien lo depuso.

45 AGI, Escribanía de Cámara, 1011A, Pleitos.

46 Ibidem. Auto dictado por la Audiencia, Santo Domingo, 4 de marzo de 1594.

47 Ibidem. Comisión de la Audiencia, Santo Domingo, 31 de octubre de 1594.

48 Ibidem. Testimonio dado por Maldonado Matute, Asunción, 22 de marzo de 1596. 
esta investigación judicial. No sólo no se prestaron a declarar ante el juez, sino que llegaron a negarse a venderle víveres por temor a la reacción de su gobernador. Silveira de la Cerda llegó a excusarse ante Maldonado por no ir a Cumaná argumentando que Vides lo había amenazado. El juez tuvo que regresar a la Margarita para continuar desde allí sus averiguaciones.

En la isla coincidió con el juez Liaño, que portaba la comisión de investigar el contrabando de Tierra Firme. Pronto pudo constatar que el gobernador de Cumaná estaba inmerso plenamente en estos negocios. ${ }^{49}$ Pero acusado no se dejó acorralar. Aprovechó la coyuntura para lanzar encendidas quejas a la Corona sobre la actuación judicial que, según él, sólo conseguía retrasar la actividad pobladora. Vides llevaba razón. El ofrecía acción rápida frente a la lentitud de la actuación judicial. Pero la Corona optó finalmente por frenar la prepotencia de su gobernador. El rey ordenó por real cédula de 3 de marzo de 1598 al juez Diego de Prado someter al onubense a un juicio de residencia. ${ }^{50}$

El juez comisionado dictó la destitución. Lo condenó, entre otras causas, por su conducta con el juez Maldonado, a pagarle los gastos, salarios y perjuicios incurridos en su comisión; ${ }^{51}$ le impuso una multa de mil pesos en favor de la Iglesia de Cumaná; ${ }^{52}$ lo remitió preso a Margarita y, aunque consiguió evadirse, finalmente fue enviado a España encadenado.

\section{El juicio de residencia y la sentencia}

Pocos meses después de dictarse la destitución, se inició el juicio de residencia contra Vides. ${ }^{53}$ El rey encomendó el proceso al doctor Diego de Prado y este juez, después de analizar el conflictivo caso, dictó 26 cargos contra el gobernador: ${ }^{54}$ entre estos se puede destacar el no haber impartido justicia con objetividad, no haber castigado pecados públicos, no obedecer cédulas y provisiones públicas, no haber quintado perlas, no haber hecho

49 Ojer: La formación..., pág. 453.

50 AGI, Escribanía de Cámara, 1011A, Pleitos. Real cédula, Madrid, 2 de marzo de 1598; y Escribanía de Cámara, 697B, Residencia.

51 Ibídem, Auto, Cumaná, 23 de abril de 1599.

52 AGI, Santo Domingo, 187. El gobernador de Cumaná, Diego Suárez de Amaya, al rey, Cumaná, 15 de junio de 1602.

53 Puede encontrarse documentación sobre la residencia en AGI, Contaduría, 1650, Escribanía, 1185A, y 697B.

54 AGI, Escribanía de Cámara, 1185A. Sentencia definitiva sobre la residencia tomada a Francisco de Vides, dada por el Consejo de Indias, Valladolid, 7 de febrero de 1603. 
poner archivo público, haber insultado y haberse ausentado. El resto tenían todos un claro beneficio económico: cobrar por otorgar oficios públicos y licencias, sobornar, vender a precio superior o pagar menos de lo debido, hacer regatonería, no abastecer a las nuevas poblaciones y haber consentido en hacer repartimientos en más cantidad de la permitida.

En las condenas dictadas por el juez encontramos algunas remisiones al dictamen del rey, a las demandas públicas, o a las sentencias sobre el caso en cuestión. En la mayor parte de los cargos se impusieron penas pecuniarias. El juez consideró oportuno recomendar a Felipe II "tener atención en el reo", ya que en las ocasiones de guerra había acudido bien y diligentemente a la defensa de aquella tierra con su persona, armas y municiones. Sin embargo, lo condenó con la privación perpetua de cargo de guerra y justicia, lo declaró indigno de los oficiales reales, y decretó su ingreso en prisión. Como se ha indicado, en la isla Margarita consiguió evadirse pero, tras el pregón que declaraba reo de alta traición a la persona que lo ocultara, volvió a prisión.

El Consejo de Indias, en su revisión de los documentos de la sentencia, dictaminó de forma más favorable al ex-gobernador. Confirmó las sentencias únicamente contra tres cargos y revocó las del resto, absolviendo a Vides, bajo el argumento de no estar suficientemente probados. Esos tres cargos eran los únicos que afectaban directamente a la Corona: no haber impartido justicia imparcialmente; no haber obedecido las órdenes públicas; y no haber efectuado el quinto real a las perlas, por valor de 1.500 ducados. Precisamente a esta última cantidad se reducía la pena pecuniaria impuesta finalmente a Vides. ${ }^{55}$

La sentencia final se dictó en 1603, pero Vides apenas pudo disfrutar de ella pues debió fallecer poco después.

\section{Conclusiones finales. La consolidación de la Nueva Andalucía tras la gobernación de Vides}

A pesar de las numerosas acusaciones a las que se había tenido que enfrentar Francisco de Vides, el Consejo de Indias, ajeno a todas las rencillas personales, optó por castigar a su valiente vasallo únicamente con una

55 AGI, Indiferente, 427. Libramiento de 1.000 ducados al receptor del Consejo de Indias, con destino a obras pías, procedentes de la condena de Vides, Valladolid, 23 de mayo de 1605. 
buena suma de dinero, tal vez por los amplios servicios que había prestado a la Corona, tanto en Caracas como en Cumaná.

Destituido el mandatario cumanés se cierra una página de la historia del Oriente Venezolano. Nueva Andalucía, bajo las gobernaciones de Serpa, Núnez Lobo y Vides, había recibido importantes aportes, tanto poblacionales como animales, que habían contribuido a su consolidación. En 1597 estaban plenamente afianzados sus dos centros poblados, Cumaná y Cumanagotos. Las fronteras eran las que definirán el desarrollo del Oriente el resto del período colonial: incorporación plena de la región de cumanagotos y desgajamiento de Trinidad. El interior de la gobernación permanecía sin colonizar, pero esta obra aún se retrasaría un largo período de tiempo. Para sustituir a Vides fue nombrado Marco Antonio Becerra, que no llegó a tomar posesión, y Diego Suárez de Amaya, que no lo hizo hasta comienzos de la siguiente centuria. Ambos se comprometerán a introducir nuevos pobladores y ganado pero, ni estos, ni sus sucesores lograrían mayores avances que los de Vides. Durante la primera mitad del siglo XVII se sucederán inútiles esfuerzos por poblar el interior. No se conseguirá hasta la segunda mitad de la centuria, cuando misioneros franciscanos y capuchinos realicen su lenta labor de evangelización y asentamiento entre los indígenas.

La economía del Oriente, aunque pobre, estaba plenamente definida. Cumaná había descuidado, y prácticamente abandonado, la explotación perlífera, pero determinó su vocación agropecuaria. El ganado aportado por los diferentes gobernadores había encontrado un lugar favorable y se desarrollaba con gran facilidad. La agricultura comenzaba a descollar, y ya se perfilaban los primeros circuitos comerciales.

La importancia estratégica también había quedado totalmente subrayada. Los holandeses extraían sal regularmente de los importantes yacimientos saliníferos de Araya. El comercio de contrabando con los naturales era un hecho constatable, y las incursiones de piratas a la ciudad de Cumaná se repitieron en diversas ocasiones. Sólo unos pocos años después, en 1622, la Corona tomaría la determinación de levantar una ingente fortaleza frente a las costas de Cumaná, sobre las Salinas de Araya, con una dotación de 300 soldados, para evitar que los extranjeros se beneficiaran de estas posesiones.

También quedaba definida la marginalidad del territorio, determinada por un retraso económico y una debilidad demográfica que singularizará la mayor parte de la época colonial. 